psychopraxis. neuropraxis $2019 \cdot 22: 2-3$

https://doi.org/10.1007/s00739-018-0538-3

(c) Springer-Verlag GmbH Austria, ein Teil von Springer Nature 2019

CrossMark

\author{
Alois Sillaber \\ Springer-Verlag GmbH, Wien, Österreich
}

\title{
Zum Herausgeberwechsel
}

sinnige Humor Prof. Fischers, der letztendlich nicht unwesentlich zur großen Produktivität von Herausgebersitzungen beitrug.

Mit dem auf eigenen Wunsch erfolgten Wechsel von der Herausgeberrolle in die Funktion eines Mitglieds im Editorial Board, die Prof. Fischer mit Beginn des Jahres 2019 nach sehr gewissenhafter und verantwortungsvoller Vorbereitung vollzog, beginnt ein neuer Abschnitt im Schicksal der psychopraxis.neuropraxis: Prof. Dr. Martin Aigner und Prof. Dr. Peter Kapeller, die bislang Mitglieder des Editorial Boards waren, sind in die Rolle der Herausgeber gewechselt und tragen ab Heft 1/2019 die Verantwortung.

Mir bleibt, mich im Namen des Springer-Verlags und aller Kolleginnen und Kollegen, die an der Zeitschrift mitwirken, aber auch ganz persönlich sehr herzlich zu bedanken: bei Prof. Fischer für die ausgezeichnete Zusammenarbeit und sein großes und unermüdliches Engagement als Herausgeber sowie für seine Bereitschaft, die Zeitschrift als Mitglied des Editorial Boards weiter zu unterstützen; bei den beiden neuen Herausgebern, Prof. Aigner und Prof. Kapeller, für ihren bisherigen großartigen Einsatz als Mitglieder im Editorial Board, aber insbesondere für ihre Bereitschaft und Zusage, die psychopraxis.neuropraxis gemeinsam weiter zu entwickeln - auf dass ihr Fatum weiterhin ein glückliches bleibe!

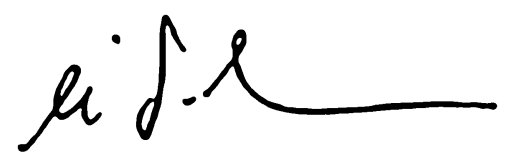

Dr. Alois Sillaber

Managing Director

Springer-Verlag

\section{Korrespondenzadresse}

Dr. Alois Sillaber

Springer-Verlag GmbH

Prinz Eugen-Straße 8-10, 1040 Wien, Österreich alois.sillaber@springer.at

Interessenkonflikt. A. Sillaber gibt an, dass kein Interessenkonflikt besteht. 
Hier steht eine Anzeige.

\section{曾 Springer}

